\title{
Substantial large-scale feedbacks between natural aerosols and climate
}

\section{Scott, Catherine}

2017-12-04

Scott , C , Arnold , S , Monks , S , Asmi , A , Paasonen , P \& Spracklen , D 2017 , ' Substantial large-scale feedbacks between natural aerosols and climate ', Nature Geoscience , vol. 11 , no. 1 , pp. 44-48 . https://doi.org/10.1038/s41561-017-0020-5

http://hdl.handle.net/10138/308161

https://doi.org/10.1038/s41561-017-0020-5

unspecified

acceptedVersion

Downloaded from Helda, University of Helsinki institutional repository.

This is an electronic reprint of the original article.

This reprint may differ from the original in pagination and typographic detail.

Please cite the original version. 


$$
\text { Scott, C. E. }{ }^{{ }^{\star}} \text {, Arnold, S.R. }{ }^{1} \text {, Monks, S.A. }{ }^{2,3} \text {, Asmi, A. }{ }^{4} \text {, Paasonen, P. }{ }^{4,5} \text {, }
$$

$$
\text { Spracklen, D.V. }{ }^{1^{*}}
$$

$5{ }^{1}$ Institute for Climate and Atmospheric Science, School of Earth and Environment, University of Leeds, Leeds, UK

$7 \quad{ }^{2}$ Cooperative Institute for Research in Environmental Sciences, University of Colorado, Boulder,

$$
\text { Colorado, USA }
$$

$9{ }^{3}$ Chemical Sciences Division, NOAA Earth System Research Laboratory, Boulder, Colorado, USA

$$
{ }^{4} \text { Department of Physics, University of Helsinki, FI-00014, Finland, }
$$

12 *email: C.E.Scott@leeds.ac.uk; D.V.Spracklen@leeds.ac.uk

14 The terrestrial biosphere is an important source of natural aerosol. Natural

15 aerosol sources alter climate, but are also strongly controlled by climate, 16 leading to the potential for natural aerosol-climate feedbacks. Here we use a

17 global aerosol model to make the first assessment of terrestrial natural aerosol-climate feedbacks, constrained by observations of aerosol number.

19 We find that warmer than average temperatures are associated with higher

20 than average number concentrations of large (> $100 \mathrm{~nm}$ diameter) particles,

21 particularly during the summer. This relationship is well reproduced by the

22 model and is driven by both meteorological variability and variability in natural

23 aerosol from biogenic and landscape fire sources. We find that the calculated

24 extra-tropical annual mean aerosol radiative effect (both direct and indirect) is 
negatively related to the observed global temperature anomaly, and is driven by a positive relationship between temperature and emission of natural aerosol. The extra-tropical aerosol-climate feedback is estimated to be $\mathbf{- 0 . 1 4}$ $\mathrm{Wm}^{-2} \mathrm{~K}^{-1}$ for landscape fire aerosol, greater than the $-0.03 \mathrm{Wm}^{-2} \mathrm{~K}^{-1}$ estimated for biogenic secondary organic aerosol. These feedbacks are comparable in magnitude to other biogeochemical feedbacks, highlighting the need for natural aerosol feedbacks to be included in climate simulations.

The terrestrial biosphere regulates atmospheric composition and climate by altering the exchange of energy, water and trace gases between the surface and atmosphere $^{1}$. The terrestrial biosphere is an important source of natural aerosols ${ }^{2}$ from vegetation fires and biogenic volatile organic compounds (BVOCs) which can form secondary organic aerosol $(\mathrm{SOA})^{3}$. These natural sources can dominate ambient aerosol in tropical ${ }^{4-7}$, temperate ${ }^{8,9}$ and boreal ${ }^{10}$ environments. Atmospheric aerosol alters the Earth's climate by absorbing and scattering radiation (direct radiative effect) and through altering the albedo of clouds (first aerosol indirect effect) ${ }^{11}$. Because natural aerosol constitutes a major fraction of ambient aerosol it can have important radiative effects ${ }^{12-15}$. The physical and biological process that control natural aerosol sources are highly sensitive to climate ${ }^{2}$. For example, changes to climate drive large changes in fire ${ }^{16-18}, \mathrm{BVOC}^{19}$ and dust ${ }^{20}$ emissions. These interactions between natural aerosol and climate create the potential for natural aerosol-climate feedbacks.

A number of natural aerosol-climate feedbacks have been proposed. The first proposed, and maybe best known, involves ocean biology and emission of dimethylsulfide ${ }^{21}$. Terrestrial aerosol-climate feedbacks have also been suggested ${ }^{1}$. 
50 Warmer temperatures drive increased BVOC emissions and increased SOA

51 concentrations, which lead to a negative radiative effect and a cooling impact on

52 climate ${ }^{22}$. Warmer temperatures also lead to increased fires and associated aerosol

53 emissions ${ }^{16}$ with impacts on climate. Observations of increased aerosol

54 concentrations with increasing ambient temperatures have been attributed to these

55 interactions ${ }^{23,24}$. However, the magnitude of natural aerosol feedbacks has rarely

56 been assessed, although large projected changes in natural aerosol under a

57 warming climate suggest that they could be substantial ${ }^{2}$. Here we explore the

58 potential magnitude of aerosol feedbacks for two terrestrial natural aerosol sources

59 with important climate impacts ${ }^{12}$ : biogenic SOA and landscape fire aerosol.

60 Exploring natural aerosol - temperature interactions

61 To explore the potential for natural aerosol-climate feedbacks, we analysed long-

62 term measurements of aerosol number made at 11 continental locations

63 (Supplementary Fig. 1) mostly across northern hemisphere mid-latitudes ${ }^{24}$. We used

64 the number concentration of particles with dry diameter larger than $100 \mathrm{~nm}\left(\mathrm{~N}_{100}\right)$ as

65 a proxy for concentrations of cloud condensation nuclei $(\mathrm{CCN})^{25}$. Particles with dry

66 diameters larger than $100 \mathrm{~nm}$ are also those that are able to scatter radiation

67 efficiently in the atmosphere.

68 At most of these locations, $\mathrm{N}_{100}$ is positively related to local surface temperature

69 (Supplementary Fig. 2) as reported previously ${ }^{24}$. We find that a global aerosol

70 microphysics model ${ }^{26}$ (see Methods) reproduces this observed relationship well

71 (Supplementary Fig. 2). To further explore the relationship between surface

72 temperature and $\mathrm{N}_{100}$, we de-seasonalised both variables. Figure 1 shows the $\mathrm{N}_{100}$

73 anomaly as a function of anomaly in local surface temperature. In summer we find

74 that most locations exhibit a strong positive relationship between temperature 
75 anomaly and anomaly in $\mathrm{N}_{100}$, with little or no relationship in winter. This means that

76 in summer, days that are warmer than average typically have higher than average

$77 \mathrm{~N}_{100}$. The global model, analysed in the same way as the observations, reproduces

78 the observed relationships (Fig. 1). The summertime mean observed sensitivity

79 between $\mathrm{N}_{100}$ and temperature, calculated across all observation stations, is

$80+51.3 \pm 5.9 \mathrm{~cm}^{-3} \mathrm{~K}^{-1}$ (linear regression based on 500 bootstrap samples) and is well

81 reproduced by the model $\left(+43.5 \pm 4.2 \mathrm{~cm}^{-3} \mathrm{~K}^{-1}\right)$. The relative anomaly in particle

82 number shows a similar relationship that is also well reproduced by the model

83 (Supplementary Fig. 3). This suggests that the model captures the processes

84 responsible for driving the observed temperature-aerosol relationships.

85 The observed relationship between temperature and aerosol number could be due to

86 interactions between natural aerosol sources and climate. However, it could also be

87 due to processes unrelated to natural aerosol sources. For example, warmer

88 temperatures could be associated with lower rainfall, and therefore reduced aerosol

89 loss via wet deposition. Or warmer temperatures could be related to transport of

90 southerly air masses towards the measurement locations, bringing more polluted air

91 with high aerosol concentrations.

92 To help interpret the observed relationships, we analysed multiple simulations from

93 the atmospheric aerosol model in which we individually switch off interannual

94 variability in natural aerosol emissions or meteorology (see Methods). At all

95 locations, we find that the simulated relationship between $\mathrm{N}_{100}$ anomaly and

96 temperature anomaly breaks down (sensitivity of $\mathrm{N}_{100}$ to temperature reduced to

$97+5.0 \pm 1.6 \mathrm{~cm}^{-3} \mathrm{~K}^{-1}$ ) when we remove interannual variability in simulated meteorology

98 (i.e., the simulation uses repeating 1997 meteorological data). This suggests that

99 meteorology is an important mechanism driving the observed relationship between 
100 anomalies in $\mathrm{N}_{100}$ and temperature. Simulations where we remove interannual

101 variability in natural aerosol emissions have less impact on the simulated relationship

102 between $\mathrm{N}_{100}$ and temperature, with sensitivity reducing to $+41.9 \pm 4.2 \mathrm{~cm}^{-3} \mathrm{~K}^{-1}$ for

103 fixed fire and $+40.9 \pm 4.0 \mathrm{~cm}^{-3} \mathrm{~K}^{-1}$ for fixed BVOC emissions (Supplementary Fig. 4).

104 We also find that if we increase simulated SOA formation from BVOCs (by a factor 5)

105 the relationship between $\mathrm{N}_{100}$ and temperature further breaks down at warm

106 temperature anomalies (Supplementary Fig. 4). This demonstrates that the

107 relationship between $\mathrm{N}_{100}$ and temperature is sensitive to the treatment of SOA in the

108 model and suggests that this treatment is adequately represented in the control

109 simulation. Overall our analysis suggests that whilst meteorology is the dominant

110 driver of observed relationships between temperature and aerosol number, variability

111 in natural aerosol emission also contributes. Our realistic simulation of the observed

112 relationships between aerosol and temperature suggests that our model treatment of

113 fire emissions and $\mathrm{SOA}^{14}$ are adequate to simulate the main interactions that are

114 important for this study.

\section{Interannual variability in aerosol radiative effects}

116 Using the multi-annual simulations of global aerosol, we explore how natural aerosol

117 sources alter the internannual variability in top-of-atmosphere aerosol radiative

118 effect. We focus on the aerosol direct radiative effect (DRE) and first aerosol indirect

119 effect (AIE), also known as the cloud albedo effect ${ }^{11}$. Other interactions between

120 aerosol and cloud are likely, but are highly uncertain ${ }^{27}$. Over the period 1997 to

1212007 , the global annual mean DRE has a standard deviation of $0.025 \mathrm{~W} \mathrm{~m}^{-2}$

122 whereas the AIE has a standard deviation of $0.017 \mathrm{~W} \mathrm{~m}^{-2}$ (Supplementary Figure 5).

123 In this control simulation, year to year variability in fire emissions are prescribed from

124 the Global Fire Emissions Dataset version 3 (GFED3) ${ }^{28}$ and BVOC emissions are 
125 calculated using MEGAN version 2.1 (ref. $^{29}$ ). To isolate the contribution of different

126 aerosol sources to this variability in the aerosol RE we individually switch off natural

127 aerosol - climate couplings (see Methods). We then use the difference between the

128 control simulation and the simulation where the interannual variability of the natural

129 aerosol source has been switched off to calculate the variability caused by each

130 natural aerosol source. Figure 2 shows the interannual variability in simulated

131 aerosol RE due to variability in biogenic SOA and fire emissions. Variability in fire

132 aerosol causes interannual variability in both DRE and AIE of greater than $0.5 \mathrm{~W} \mathrm{~m}^{-2}$

133 over and downwind of regions of tropical and boreal fires. Interannual variability in

134 biogenic SOA causes smaller variability in RE, with variability of up to $0.2 \mathrm{~W} \mathrm{~m}^{-2}$ over

135 the SE United States and tropical forest regions. Landscape fires have also been

136 shown to control interannual variability in regional surface carbonaceous aerosol

137 concentrations $^{9}$ and aerosol optical depth ${ }^{30}$.

138 Figure 2 shows that some of the largest simulated radiative impacts caused by

139 variability in natural aerosol are in the tropics. However, our understanding of

140 atmospheric composition and emissions of natural aerosol in the tropics is still poor.

141 There are very few long-term studies of aerosol size distribution in the tropical

142 atmosphere and none of our 11 stations are in the tropics (defined here as $20^{\circ} \mathrm{S}$ to

$14320^{\circ} \mathrm{N}$ ). The tropics are thought to be the dominant source of both $\mathrm{BVOC}^{29}$ and fire ${ }^{28}$

144 emissions. However, there have been few studies of BVOC emissions in the tropics.

145 A study in the Amazon, confirmed the importance of temperature, light and leaf

146 phenology in driving BVOC emissions but also suggested our mechanistic

147 understanding of BVOC emissions in the tropics is still limited ${ }^{31}$. The chemical

148 composition of monoterpene emissions in the tropics may also vary with

149 temperature, with reactive isomers being enriched at high temperatures ${ }^{32,33}$ with 
150 potential consequences for SOA. For these reasons we focus on the extra-tropical

$151\left(>20^{\circ} \mathrm{S}\right.$ and $\left.>20^{\circ} \mathrm{N}\right) \mathrm{RE}$, where there is less uncertainty in BVOC emissions and we

152 have observations to constrain the sensitivity of the aerosol model to natural aerosol.

153 We explored the control on the variability in aerosol RE over the period 1997 to 2007

154 (see Methods). We find that there is a negative correlation between global (land and

155 ocean) surface temperature anomaly and the anomaly in extra-tropical annual mean

156 DRE (Pearson's $r=-0.74, P<0.01)$ and AIE $(r=-0.52, P<0.1)$ (Supplementary Table

157 1). Figure 3 shows the anomaly in RE due to variability in biogenic SOA and fire

158 aerosol as a function of the anomaly in annual global temperature (see Methods).

159 We find an even stronger negative correlation between the global temperature

160 anomaly and anomaly in extra-tropical annual mean RE from biogenic SOA, both for

161 the DRE $(r=-0.76, P<0.01)$ and AIE $(r=-0.71, P<0.01)$. Simulated emissions of BVOC

162 are strongly controlled by temperature ${ }^{29}$; we find a strong positive correlation

163 between annual extra-tropical BVOC emission and global temperature anomaly

164 (monoterpene $r=0.78$; isoprene $r=0.79$ ) (Supplementary Figure 7 ). Warmer than

165 average years drive increased BVOC emissions leading to increased formation of

166 SOA, which results in a stronger negative DRE and AIE.

167 We also simulate a negative correlation between global temperature anomaly and

168 the anomaly in the extra-tropical RE from fire, both for the DRE $(r=-0.5, P<0.1)$ and

169 AIE $(r=-0.51, P<0.05)$. We find a positive correlation between annual extra-tropical

170 particulate emission from landscape fires and global temperature anomaly $(r=0.39)$

171 (Supplementary Fig. 7). The correlation between temperature anomaly and RE from

172 fires is weaker compared to BVOC, due to this weaker correlation between

173 temperature and fire emission. Global fire activity is governed by a complex suite of

174 climate, natural and human ignition sources and available fuel ${ }^{18}$. Whilst years with 
175 warm temperature anomalies are associated with greater fire emissions, other

176 climate variables such as rainfall and relative humidity are also important ${ }^{18,34}$.

\section{Diagnosing natural aerosol-climate feedbacks}

178 We used the relationship between $\mathrm{RE}$ and global temperature anomaly to estimate

179 the aerosol radiative feedback $(\lambda)$ for the different natural aerosol sources, following

180 the framework of previous work ${ }^{1}$ (see Methods). In this framework climate feedbacks

181 are expressed in common units of $\mathrm{W} \mathrm{m}^{-2} \mathrm{~K}^{-1}$ and are shown in Figure 4. We estimate

182 that fire results in an extra-tropical direct aerosol radiative feedback of $-0.09 \pm 0.06 \mathrm{~W}$

$183 \mathrm{~m}^{-2} \mathrm{~K}^{-1}$ and an extra-tropical indirect aerosol radiative feedback of $-0.06 \pm 0.03 \mathrm{~W} \mathrm{~m}^{-2}$

$184 \mathrm{~K}^{-1}$. We estimate a smaller radiative feedback due to biogenic SOA, with an extra-

185 tropical direct radiative feedback of $-0.02 \pm 0.01 \mathrm{~W} \mathrm{~m}^{-2} \mathrm{~K}^{-1}$ and an extra-tropical

186 indirect aerosol radiative feedback of $-0.007 \pm 0.002 \mathrm{~W} \mathrm{~m}^{-2} \mathrm{~K}^{-1}$.

187 Figure 4 also shows our estimates of the global radiative feedbacks. The global

188 aerosol feedback for fire aerosol is relatively similar to that calculated for the extra-

189 tropics. In contrast, the global biogenic SOA feedback is about double the strength of

190 that calculated in the extra-tropics (Fig. 4). We note that we have no observational

191 constraint of the natural aerosol feedback in the tropics, and so these global

192 estimates are unconstrained. Long-term observations of BVOC emissions and

193 aerosol concentrations in the tropics are urgently needed.

194 The stronger fire aerosol radiative feedback compared to the biogenic SOA feedback

195 is primarily due to the stronger interannual variability of fire emissions compared to

196 BVOCs. The coefficient of variation (standard deviation divided by mean) for global

197 particulate emission from fire is $19.6 \%$ (Supplementary Fig. 7 and Methods). The

198 simulated coefficient of variation for BVOC emissions is substantially smaller both for

199 isoprene emissions (2.9\%) and for monoterpene emissions (2.4\%). Our simulated 
200 interannual variability in BVOC emissions and biogenic SOA matches previous 201 work $^{35}$. The absolute variability in both BVOC and particulate emissions from fire is 202 greatest in the tropics, but the extra-tropics exhibits greater fractional variability 203 (Supplementary Fig. 6 and 7).

204 We find that the direct radiative feedback is stronger than the indirect radiative 205 feedback for both natural aerosol sources. This behaviour is particularly true for 206 biogenic SOA where the direct aerosol feedback is more than a factor 3 greater than 207 the indirect aerosol feedback. We note that our estimated direct aerosol feedback for 208 fires will depend on the net DRE of fire aerosol which is uncertain ${ }^{36}$. The relatively 209 weak aerosol indirect feedback for biogenic SOA is due to the AIE being relatively 210 insensitive to emission of BVOC ${ }^{12,14}$. The global biogenic SOA feedback from 211 aerosol indirect effect that we estimate here $\left(-0.013 \pm 0.002 \mathrm{~W} \mathrm{~m}^{-2} \mathrm{~K}^{-1}\right)$ is similar to 212 the global mean value of $-0.01 \mathrm{~W} \mathrm{~m}^{-2} \mathrm{~K}^{-1}$ inferred from selected observations ${ }^{24}$.

213 Our estimate of natural aerosol - climate feedbacks is applicable for the present day 214 and may be different in future or past climates. Climate change and increased 215 atmospheric carbon dioxide concentrations will alter the amount and type of 216 vegetation ${ }^{37,38}$, altering both BVOC $^{29}$ and fire emissions ${ }^{39,40}$. Changes in 217 environmental factors in a warming climate may lead to stressed vegetation and 218 additional BVOC emissions, potentially creating stronger couplings between 219 vegetation, aerosol and climate ${ }^{41}$. Increased $\mathrm{CO}_{2}$ concentrations may alter BVOC 220 emissions $^{29}$, altering biogenic SOA and associated feedbacks. Feedbacks can also 221 be directly altered by human activity. Land-use change and land management have 222 altered BVOC and fire emissions since pre-human times ${ }^{42}$. Anthropogenic aerosol 223 suppresses natural aerosol - climate interactions ${ }^{43}$, meaning natural aerosol - climate 224 feedbacks may strengthen with future reductions in anthropogenic aerosol 
225 emissions. Additional feedbacks between the biosphere, BVOC, fire emissions and 226 climate operating through precipitation and soil moisture are possible, but are not 227 included here.

228 The strength of natural aerosol feedbacks is comparable in magnitude to a range of 229 other biogeochemical feedbacks ${ }^{1}$ and is opposite in sign to the global snow-albedo 230 feedback which has been estimated as $+0.1 \mathrm{~W} \mathrm{~m}^{-2} \mathrm{~K}^{-1}\left(\right.$ ref. $\left.^{44}\right)$. Our findings suggest 231 that natural aerosol-climate feedbacks may play a role in moderating net 232 temperature response to $\mathrm{CO}_{2}$-driven or other external forcings, and should be 233 included in fully-coupled simulations of past and future climate. 


\section{References}

248

2491 Arneth, A. et al. Terrestrial biogeochemical feedbacks in the climate system.

250

251

2 Carslaw, K. S. et al. A review of natural aerosol interactions and feedbacks

252

253

254

255

256

257

258

259

260

261

262

263

264

265

266

267

268

269

270

271

272

273

274

275

276

277

278

279

280

281

282

283

284

285

286 within the Earth system. Atmos. Chem. Phys. 10, 1701-1737, doi:10.5194/acp-10-1701-2010 (2010).

3 Hallquist, M. et al. The formation, properties and impact of secondary organic aerosol: current and emerging issues. Atmos. Chem. Phys. 9, 5155-5236 (2009).

4 Poschl, U. et al. Rainforest Aerosols as Biogenic Nuclei of Clouds and Precipitation in the Amazon. Science 329, 1513-1516, doi:10.1126/science.1191056 (2010).

5 Martin, S. T. et al. SOURCES AND PROPERTIES OF AMAZONIAN AEROSOL PARTICLES. Reviews of Geophysics 48, doi:10.1029/2008rg000280 (2010).

6 Martin, S. T. et al. Introduction: Observations and Modeling of the Green Ocean Amazon (GoAmazon2014/5). Atmos. Chem. Phys. 16, 4785-4797, doi:10.5194/acp-16-4785-2016 (2016).

7 Andreae, M. O. et al. The Amazon Tall Tower Observatory (ATTO): overview of pilot measurements on ecosystem ecology, meteorology, trace gases, and aerosols. Atmos. Chem. Phys. 15, 10723-10776, doi:10.5194/acp-15-107232015 (2015).

8 Goldstein, A. H., Koven, C. D., Heald, C. L. \& Fung, I. Y. Biogenic carbon and anthropogenic pollutants combine to form a cooling haze over the southeastern United States. Proceedings of the National Academy of Sciences of the United States of America 106, 8835-8840, doi:10.1073/pnas.0904128106 (2009).

9 Spracklen, D. V. et al. Wildfires drive interannual variability of organic carbon aerosol in the western US in summer. Geophys. Res. Lett. 34, doi:10.1029/2007gl030037 (2007).

10 Tunved, P. et al. High natural aerosol loading over boreal forests. Science 312, 261-263, doi:10.1126/science.1123052 (2006).

11 Twomey, S. Aerosols, clouds and radiation. Atmospheric Environment 25, 2435-2442 (1991).

12 Rap, A. et al. Natural aerosol direct and indirect radiative effects. Geophys. Res. Lett. 40, 3297-3301, doi:10.1002/grl.50441 (2013).

13 Satheesh, S. K. \& Moorthy, K. K. Radiative effects of natural aerosols: A review. Atmospheric Environment 39, 2089-2110, doi:10.1016/j.atmosenv.2004.12.029 (2005). 
14 Scott, C. E. et al. The direct and indirect radiative effects of biogenic secondary organic aerosol. Atmos. Chem. Phys. 14, 447-470, doi:10.5194/acp-14-447-2014 (2014).

290

15 Unger, N. Human land-use-driven reduction of forest volatiles cools global climate. Nat. Clim. Chang. 4, 907-910, doi:10.1038/nclimate2347 (2014).

293

294

295

296

297

298

299

300

301

302

303

304

305

306

307

308

309

310

311

312

313

314

315

316

317

318

319

320

321

322

323

324

325

326

$327 \quad 27$

328

$329 \quad 28$

330

Spracklen, D. V. et al. Impacts of climate change from 2000 to 2050 on wildfire activity and carbonaceous aerosol concentrations in the western United States. J. Geophys. Res.-Atmos. 114, doi:10.1029/2008jd010966 (2009).

17 Ward, D. S. et al. The changing radiative forcing of fires: global model estimates for past, present and future. Atmos. Chem. Phys. 12, 10857-10886, doi:10.5194/acp-12-10857-2012 (2012).

18 Jolly, W. M. et al. Climate-induced variations in global wildfire danger from 1979 to 2013. Nat. Commun. 6, 11, doi:10.1038/ncomms8537 (2015).

19 Heald, C. L. et al. Predicted change in global secondary organic aerosol concentrations in response to future climate, emissions, and land use change. J. Geophys. Res.-Atmos. 113, 16, doi:10.1029/2007jd009092 (2008).

20 Mahowald, N. M. et al. Change in atmospheric mineral aerosols in response to climate: Last glacial period, preindustrial, modern, and doubled carbon dioxide climates. J. Geophys. Res.-Atmos. 111, 22, doi:10.1029/2005jd006653 (2006).

21 Charlson, R. J., Lovelock, J. E., Andreae, M. O. \& Warren, S. G. OCEANIC PHYTOPLANKTON, ATMOSPHERIC SULFUR, CLOUD ALBEDO AND CLIMATE. Nature 326, 655-661, doi:10.1038/326655a0 (1987).

22 Kulmala, M. et al. A new feedback mechanism linking forests, aerosols, and climate. Atmos. Chem. Phys. 4, 557-562 (2004).

23 Lihavainen, H., Asmi, E., Aaltonen, V., Makkonen, U. \& Kerminen, V. M. Direct radiative feedback due to biogenic secondary organic aerosol estimated from boreal forest site observations. Environ. Res. Lett. 10, 8, doi:10.1088/1748-9326/10/10/104005 (2015).

24 Paasonen, P. et al. Warming-induced increase in aerosol number concentration likely to moderate climate change. Nat. Geosci. 6, 438-442, doi:10.1038/ngeo1800 (2013).

25 Dusek, U. et al. Size Matters More Than Chemistry for Cloud-Nucleating Ability of Aerosol Particles. Science 312, 1375-1378, doi:10.1126/science.1125261 (2006).

26 Mann, G. W. et al. Description and evaluation of GLOMAP-mode: a modal global aerosol microphysics model for the UKCA composition-climate model. Geoscientific Model Development 3, 519-551, doi:10.5194/gmd-3-519-2010 (2010).

27 Lohmann, U. \& Feichter, J. Global indirect aerosol effects: a review. Atmos. Chem. Phys. 5, 715-737 (2005).

28 van der Werf, G. R. et al. Global fire emissions and the contribution of deforestation, savanna, forest, agricultural, and peat fires (1997-2009). 
Atmos. Chem. Phys. 10, 11707-11735, doi:10.5194/acp-10-11707-2010 (2010).

29 Guenther, A. B. et al. The Model of Emissions of Gases and Aerosols from Nature version 2.1 (MEGAN2.1): an extended and updated framework for modeling biogenic emissions. Geoscientific Model Development 5, 14711492, doi:10.5194/gmd-5-1471-2012 (2012).

30 Voulgarakis, A. et al. Interannual variability of tropospheric trace gases and aerosols: The role of biomass burning emissions. J. Geophys. Res.-Atmos. 120, 7157-7173, doi:10.1002/2014jd022926 (2015).

31 Alves, E. G. et al. Seasonality of isoprenoid emissions from a primary rainforest in central Amazonia. Atmos. Chem. Phys. 16, 3903-3925 (2016).

32 Jardine, K. J. et al. Monoterpene 'thermometer' of tropical forest-atmosphere response to climate warming. Plant, Cell \& Environment 40, 441-452, doi:10.1111/pce.12879 (2017).

33 Jardine, A. B. et al. Highly reactive light-dependent monoterpenes in the Amazon. Geophys. Res. Lett. 42, 1576-1583, doi:10.1002/2014GL062573 (2015).

34 van der Werf, G. R., Randerson, J. T., Giglio, L., Gobron, N. \& Dolman, A. J. Climate controls on the variability of fires in the tropics and subtropics. Glob. Biogeochem. Cycle 22, 13, doi:10.1029/2007gb003122 (2008).

35 Tsigaridis, K., Lathiere, J., Kanakidou, M. \& Hauglustaine, D. A. Naturally driven variability in the global secondary organic aerosol over a decade. Atmos. Chem. Phys. 5, 1891-1904 (2005).

36 Myhre, G. et al. Radiative forcing of the direct aerosol effect from AeroCom Phase II simulations. Atmos. Chem. Phys. 13, 1853-1877, doi:10.5194/acp13-1853-2013 (2013).

37 Zhu, Z. C. et al. Greening of the Earth and its drivers. Nat. Clim. Chang. 6 , 791-795, doi:10.1038/nclimate3004 (2016).

38 Zaehle, S., Jones, C. D., Houlton, B., Lamarque, J. F. \& Robertson, E. Nitrogen Availability Reduces CMIP5 Projections of Twenty-First-Century Land Carbon Uptake. Journal of Climate 28, 2494-2511, doi:10.1175/jcli-d-1300776.1 (2015).

39 Kloster, S. \& Lasslop, G. Historical and future fire occurrence (1850 to 2100) simulated in CMIP5 Earth System Models. Glob. Planet. Change 150, 58-69, doi:10.1016/j.gloplacha.2016.12.017 (2017).

40 Hantson, S. et al. The status and challenge of global fire modelling. Biogeosciences 13, 3359-3375, doi:10.5194/bg-13-3359-2016 (2016).

41 Zhao, D. F. et al. Environmental conditions regulate the impact of plants on cloud formation. Nat. Commun. 8, 8, doi:10.1038/ncomms14067 (2017).

42 Heald, C. L. \& Spracklen, D. V. Land Use Change Impacts on Air Quality and Climate. Chem. Rev. 115, 4476-4496, doi:10.1021/cr500446g (2015).

43 Spracklen, D. V. \& Rap, A. Natural aerosol-climate feedbacks suppressed by anthropogenic aerosol. Geophys. Res. Lett. 40, 5316-5319, doi:10.1002/2013gl057966 (2013). 
37544 Thackeray, C. W. \& Fletcher, C. G. Snow albedo feedback: Current knowledge, importance, outstanding issues and future directions. Prog. Phys.

377 Geogr. 40, 392-408, doi:10.1177/0309133315620999 (2016).

378

379

380 Acknowledgements

381 We acknowledge support from the Natural Environment Research Council

382 (NE/K015966/1) and EU Horizon 2020 (SC5-01-2014; grant agreement no 641816).

383 This work used the ARCHER UK National Supercomputing Service

384 (http://www.archer.ac.uk).

385 Author contributions

386 All authors contributed to the research design. CS and SM performed model

387 simulations. AA and PP provided observational data. CS, DS and SA analysed the 388 data. All authors contributed to scientific discussions and helped to write the 389 manuscript.

$390 \quad$ Additional information

391 Supplementary information is available in the online version of the paper.

392 Correspondence and requests for materials should be sent to CS.

393 Competing financial interests

394 The authors declare no competing financial interests.

395 Figure captions

396 Figure 1. Relationship between particle number anomaly and temperature

397 anomaly. The particle number anomaly is for particles greater than $100 \mathrm{~nm}$ diameter

$398\left(\mathrm{~N}_{100}\right)$. Winter (top panels: $\left.\mathrm{a}, \mathrm{b}\right)$ and summer (bottom panels: $\mathrm{c}, \mathrm{d}$ ) are shown for 399 observations (left: a, c) and model (right: b, d). Each observation is represented by a 
400 point (left), whilst the lines represent the median $\mathrm{N}_{100}$ anomaly per $2 \mathrm{~K}$ temperature 401 anomaly bin. Different locations are indicated by the different lines (see key). All 402 stations except one are in the Northern Hemisphere where winter is December to 403 February and summer is July to August. For the one station in the Southern 404 Hemisphere we show July to August as winter and December to February as 405 summer.

406 Figure 2. Interannual variability in aerosol radiative effect (RE). (a, b) Direct 407 radiative effect, $(c, d)$ aerosol indirect effect shown for biogenic SOA (a, c) and fire $408(b, d)$. Numbers on the panels show the standard deviation in global annual mean 409 RE over the period $1997-2007$.

410 Figure 3. Relationship between aerosol radiative effect (RE) and global

411 temperature anomaly. (a) Direct radiative effect, (b) aerosol indirect effect shown 412 for biogenic SOA (blue) and fire (red). Symbols show results for the extra-tropics $413\left(>20^{\circ} \mathrm{N}\right.$ and $>20^{\circ} \mathrm{S}$ ). Linear fits are shown for the extra-tropics (solid line) and at the 414 global scale (dashed line). Number on panel shows correlation ( $r$ ) between RE and 415 temperature anomaly. Temperature anomalies are calculated relative to a 1971 to 4162000 climatology.

417 Figure 4. Simulated natural aerosol feedback. Values are shown for biogenic 418 SOA (blue) and fire (red). Solid bars show the extra-tropical feedback $\left(>20^{\circ} \mathrm{N}\right.$ and $419>20^{\circ} \mathrm{S}$ ), dashed bars show the global feedback. Error bar shows standard error in 420 the estimated feedback (based on 500 bootstrap samples).

\section{Methods}

422 Observations: We used long term observations of the number concentration of 423 particles larger than $100 \mathrm{~nm}$ in diameter $\left(\mathrm{N}_{100}\right)$ and surface temperature from 11 
424 surface stations. The observations are as described in ref. ${ }^{24}$. We de-seasonalised

425 both $\mathrm{N}_{100}$ and temperature through subtracting the long-term monthly mean from the

426 original data. We calculated the sensitivity of $\mathrm{N}_{100}$ to surface temperature between an

427 anomaly of $-10 \mathrm{~K}$ and $+10 \mathrm{~K}$.

428 Aerosol model: We used the TOMCAT chemical transport model coupled to the

429 GLOMAP-mode aerosol microphysics model ${ }^{26}$ to simulate the distribution of

430 atmospheric aerosol over the period 1997-2007. Fire emissions were from GFEDv3,

431 based on burned area, active fire detections and plant productivity from the

432 MODerate resolution Imaging Spectroradiometer (MODIS) ${ }^{28}$. Emissions of isoprene

433 and monoterpenes were calculated using MEGANv2.1 (ref. ${ }^{29}$ ) in the Community

434 Land Model (CLMv4.5). Emissions depend on the distribution of vegetation, $\mathrm{CO}_{2}$

435 concentration, solar radiation, temperature and moisture. Anthropogenic aerosol

436 emissions and precursors were from the MACCity datase $t^{45}$. Other natural aerosol

437 and aerosol precursor emissions include oceanic DMS emissions calculated using a

438 sea-air transfer velocity ${ }^{46}$ and a sea surface concentration database ${ }^{47}$, sea-spray

439 emissions $^{48}$ and volcanic sulphur emissions ${ }^{49}$. GLOMAP was forced with ERA-

440 Interim analyses from the European Centre for Medium Range Weather Forecasts

441 (ECMWF). We use offline oxidant concentrations from the TOMCAT chemical

442 transport model. Here GLOMAP has a horizontal resolution of $2.8^{\circ} \times 2.8^{\circ}$ and 31

443 vertical levels between the surface and $10 \mathrm{hPa}$. The model simulates aerosol

444 component mass and number concentration (two-moment modal) in seven

445 lognormal modes: hygroscopic nucleation, Aitken, accumulation, coarse, and non-

446 hygroscopic Aitken, accumulation and coarse modes. The modal version of the

447 model matches a more computationally expensive sectional scheme ${ }^{50}$. Secondary

448 organic aerosol (SOA) is formed from the oxidation of monoterpenes and isoprene 
449 and is treated as described in ref. ${ }^{14}$. The oxidation products of monoterpenes are

450 able to participate in new particle formation ${ }^{51}$ and growth whereas the oxidation

451 products of isoprene contribute only to condensational growth. A control simulation

452 where emissions and meteorology varied according to simulation year was

453 compared against simulations where one specific emission or process was fixed to

4541997 values. These were a) anthropogenic emissions, b) biogenic VOC emissions,

455 c) landscape fire emissions, d) ERA-Interim fields. All simulations were run for the 456 period 1997 to 2007.

457 Radiation model: Top-of-atmosphere, all-sky aerosol radiative effects (RE) were 458 calculated using the Suite of Community Radiative Transfer codes (SOCRATES) ${ }^{52}$. 459 We calculated the direct radiative effect (DRE) and the aerosol indirect effect (AIE) 460 resulting from changes to cloud droplet number concentration. Full details are 461 provided in ref. $^{14}$.

462 Aerosol RE were calculated for all five aerosol model simulations that are described 463 above. The global annual mean RE was calculated for each simulation. The anomaly 464 in global annual mean radiative effect was calculated with respect to the start year of 465 the simulation (1997). We then calculated global annual mean RE anomaly for each 466 emission or process as the difference in global mean RE anomaly between the 467 control simulation and the simulation where that process had been fixed to 1997 468 values. The sum of RE anomaly from the four simulations agreed with the RE 469 anomaly from the control simulation to within $2 \%$.

470 Climate feedback: Global annual temperature anomalies $(\Delta T)$ are from the National 471 Oceanic and Atmospheric Administration (NOAA). We used the NOAA Merged Land 472 Ocean Global Surface Temperature Analysis Dataset (NOAAGlobalTemp v4.0.1) ${ }^{53}$, 473 a spatially gridded $\left(5^{\circ} \times 5^{\circ}\right)$ global surface temperature dataset. Temperature 
474 anomalies were calculated over land and ocean with respect to the 1971 to 2000

475 climatology. The Pearson's correlation ( $r$ ) between $\Delta R E$ and $\Delta T$ was calculated for 476 each simulation.

477 We calculate the climate feedback $(\lambda)$ following previous work ${ }^{1}$. Climate feedbacks, 478 expressed in units of $\mathrm{W} \mathrm{m}^{-2} \mathrm{~K}^{-1}$, are calculated for each natural aerosol as the 479 change in top-of-atmosphere radiative effect $(\triangle R E)$ divided by the change in global 480 mean surface temperature ( $\Delta T$ ) (i.e., $\lambda=\Delta R E / \Delta T$ ), determined from the gradient of 481 the best fit line between the $\Delta R E$ and $\Delta T$. Uncertainty in the calculated feedback is 482 estimated using a bootstrapping approach, based on 500 bootstrap samples.

483 Data availability: The NOAA Merged Land Ocean Global Surface Temperature 484 Analysis Dataset (NOAAGlobalTemp v4.0.1) is available online 485 (https://www.ncdc.noaa.gov/data-access/marineocean-data/noaa-global-surface486 temperature-noaaglobaltemp). Data from our model simulations are available upon 487 request.

488 Code availability: A request for the code used to generate these results can be 489 made via http://www.ukca.ac.uk/wiki/index.php/Main_Page

45 Granier, C. et al. Evolution of anthropogenic and biomass burning emissions of air pollutants at global and regional scales during the 1980-2010 period. Clim. Change 109, 163-190, doi:10.1007/s10584-011-0154-1 (2011).

46 Nightingale, P. D. et al. In situ evaluation of air-sea gas exchange parameterizations using novel conservative and volatile tracers. Glob. Biogeochem. Cycle 14, 373-387, doi:10.1029/1999GB900091 (2000). comparison of updated data sets and flux models. Journal of Geophysical Research: Atmospheres 105, 26793-26808, doi:10.1029/2000JD900252 (2000). 
502

503

504

505

506

507

508

509

510

511

512

513

514

515

516

517

518

519

520

521

522

523

524

525

526

527

528

529

530
48 Gong, S. L. A parameterization of sea-salt aerosol source function for suband super-micron particles. Glob. Biogeochem. Cycle 17, 1097, doi:10.1029/2003GB002079 (2003).

49 Dentener, F. et al. Emissions of primary aerosol and precursor gases in the years 2000 and 1750 prescribed data-sets for AeroCom. Atmos. Chem. Phys. 6, 4321-4344, doi:10.5194/acp-6-4321-2006 (2006).

50 Mann, G. W. et al. Intercomparison of modal and sectional aerosol microphysics representations within the same 3-D global chemical transport model. Atmos. Chem. Phys. 12, 4449-4476, doi:10.5194/acp-12-4449-2012 (2012).

51 Metzger, A. et al. Evidence for the role of organics in aerosol particle formation under atmospheric conditions. Proceedings of the National Academy of Sciences of the United States of America 107, 6646-6651, doi:10.1073/pnas.0911330107 (2010).

52 Edwards, J. M. \& Slingo, A. Studies with a flexible new radiation code 1. Choosing a configuration for a large-scale model. Q. J. R. Meteorol. Soc. 122, 689-719, doi:10.1002/qj.49712253107 (1996).

53 Smith, T. M., Reynolds, R. W., Peterson, T. C. \& Lawrimore, J. Improvements to NOAA's Historical Merged Land-Ocean Surface Temperature Analysis (1880-2006). Journal of Climate 21, 2283-2296, doi:10.1175/2007jcli2100.1 (2008). 

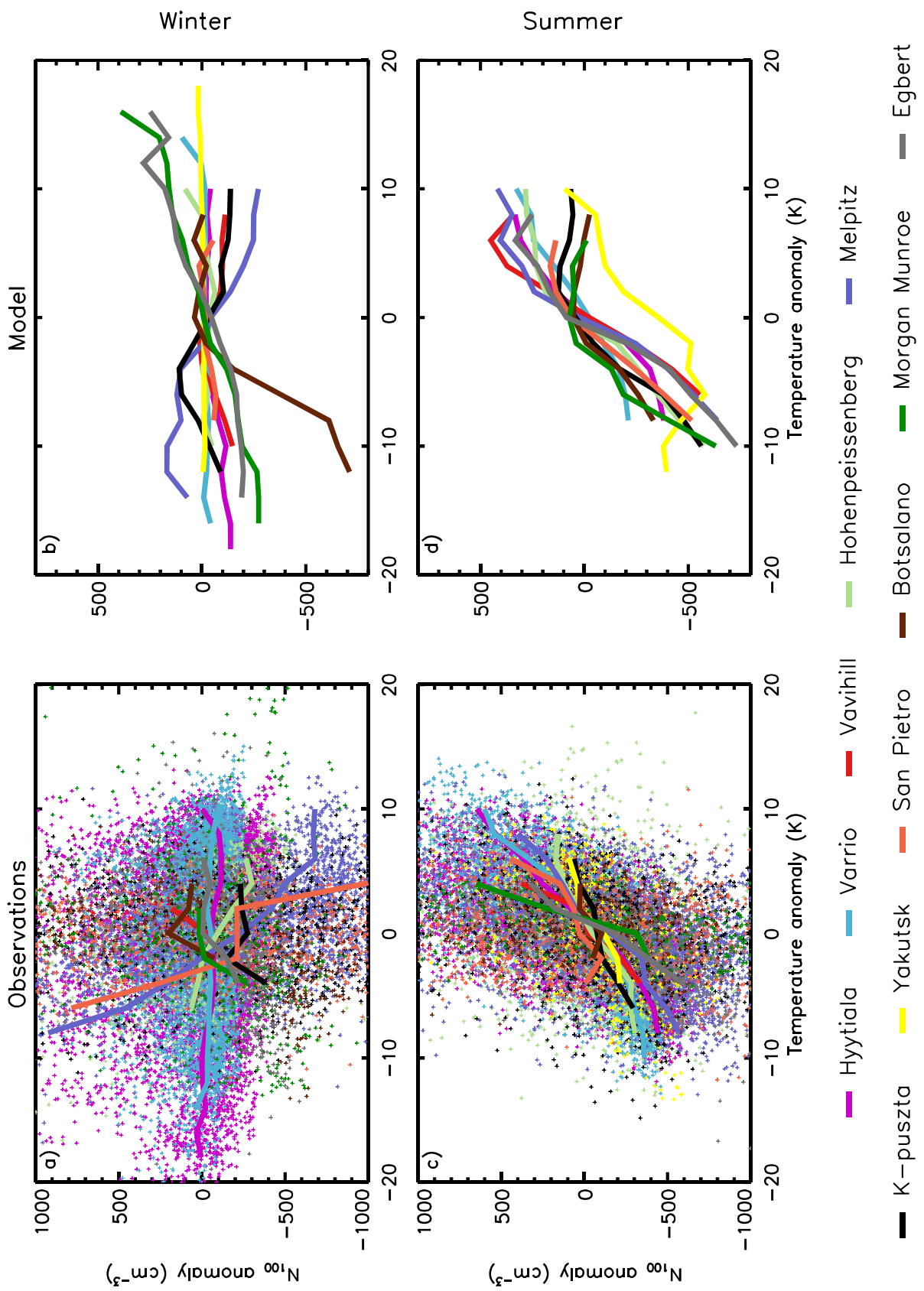

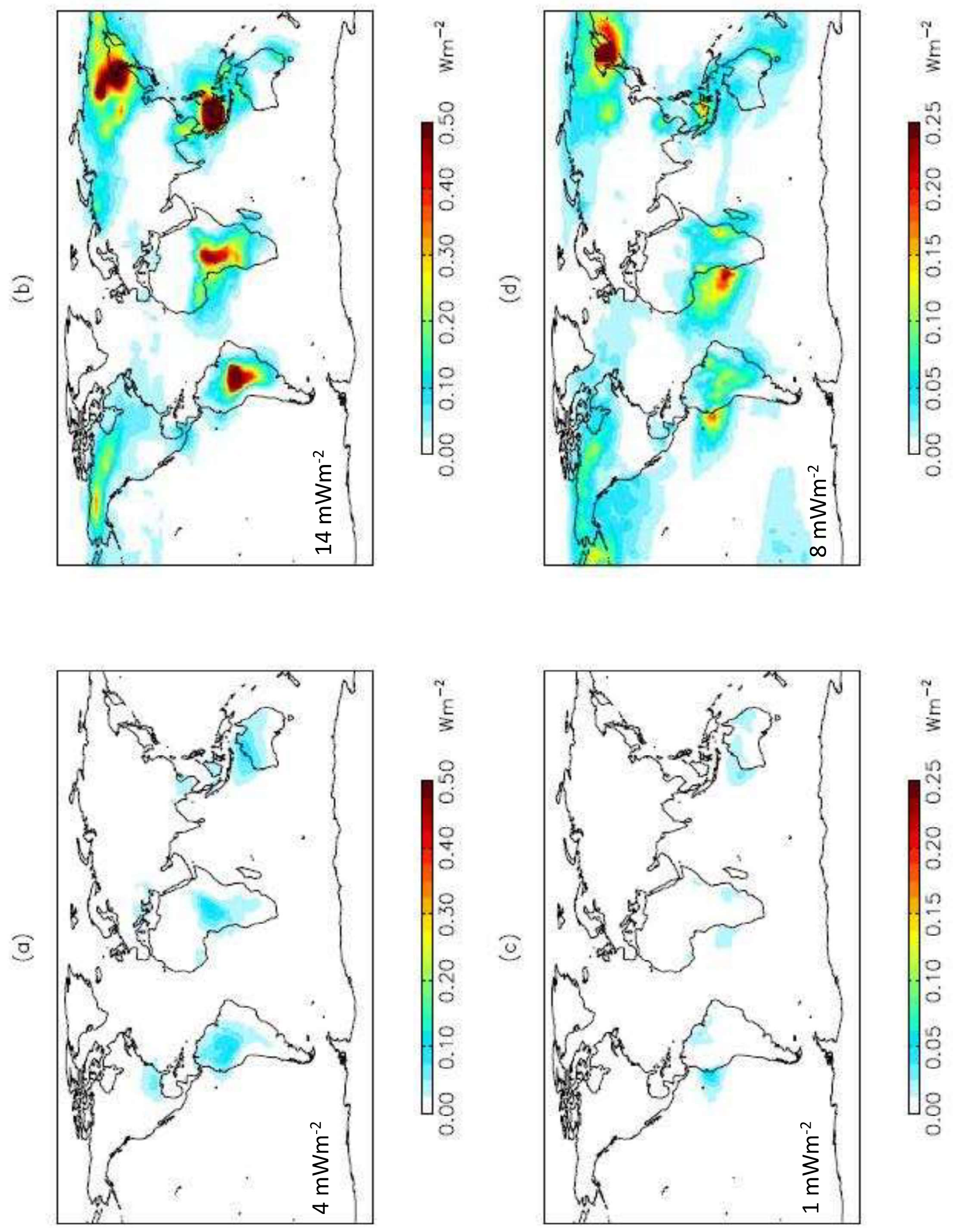

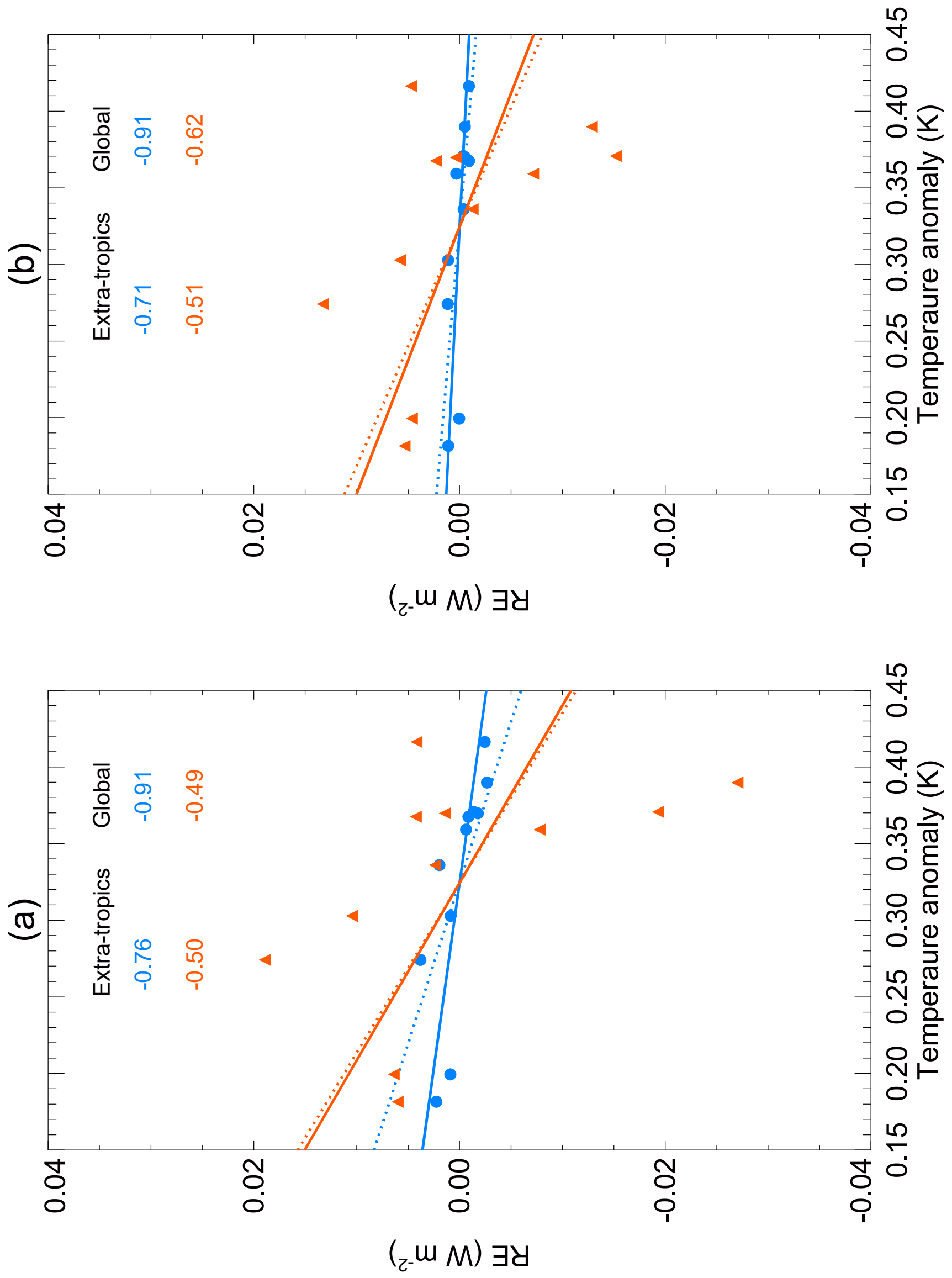


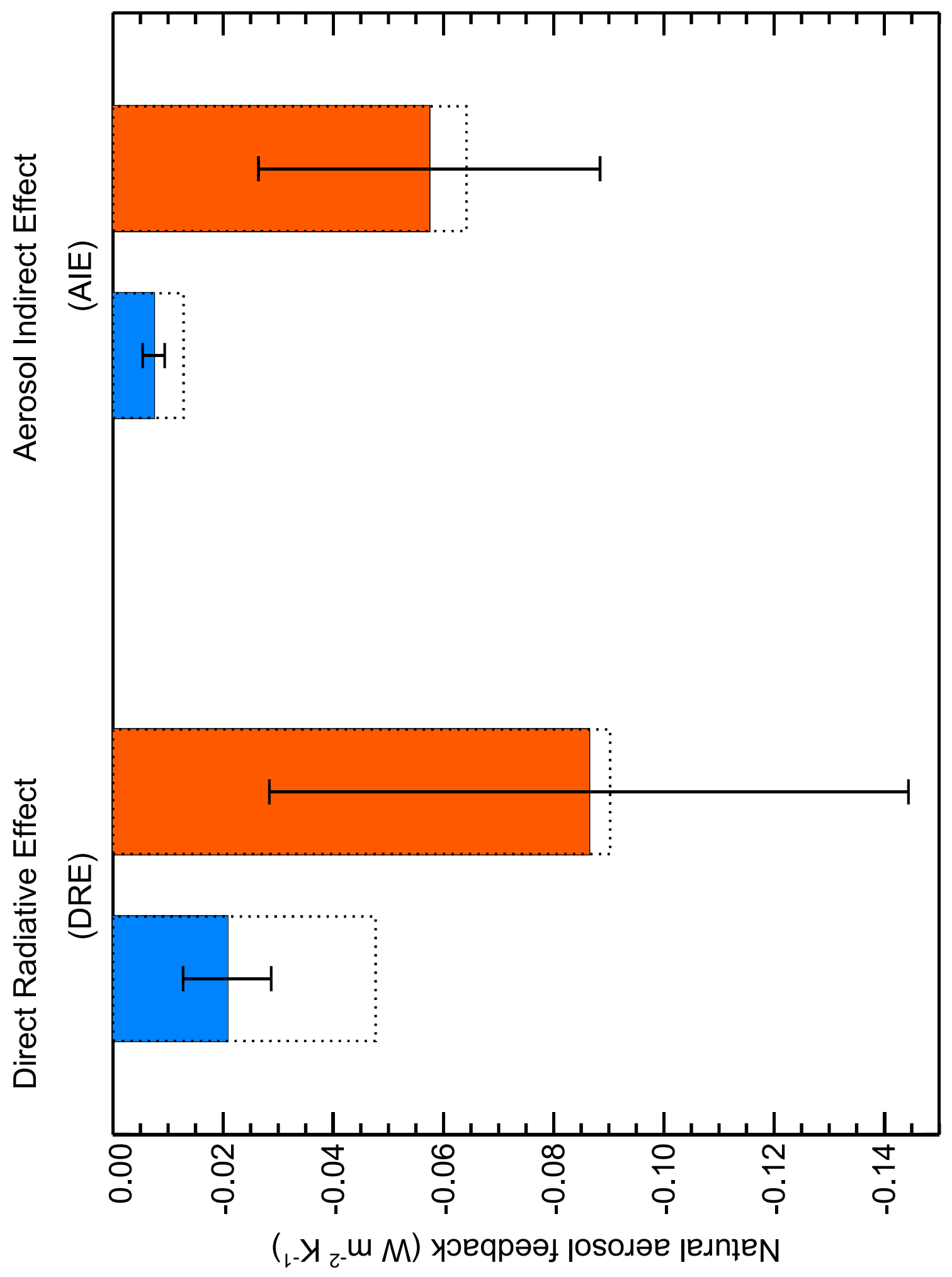

